\title{
White House backs US contribution to LHC
}

Washington. The Clinton administration has decided to back a US contribution of $\$ 530$ million towards construction of the Large Hadron Collider (LHC) at CERN, the European particle physics laboratory in Geneva, Switzerland.

Details of the proposed contribution will be spelt out in the federal budget for the 1998 financial year (which starts on 1 October 1997), due to be unveiled next month. Administration officials will then seek congressional support for the contribution, which would be the largest ever by the United States to a scientific project overseas.

Officials at the Department of Energy have been negotiating with CERN while battling to secure US backing for the project. They received confirmation that the administration will support them early last month, when the White House Office of Management and Budget (OMB) accepted their proposed budget for highenergy and nuclear physics for 1998.

"Our challenge has been to convince OMB that our programmes deserve to be treated like those of the National Institutes of Health and the National Science Foundation," says Martha Krebs, director of research at the energy department. The Clinton administration has exempted those agencies from budget cuts. "The early indications are that we have been quite successful, at least for most of our programmes."

Krebs declines to discuss specific figures before next month's budget announcement. But other sources say that OMB has agreed to hold steady spending on nuclear and high-energy physics at close to the 1997 level of \$1 billion.

The administration had previously published projections that would have sharply reduced spending in 1998 and later years, in line with large overall reductions that it has promised for the energy departent.

The department plans to spend $\$ 200$ million on the construction of the LHC and $\$ 250$ million on its two detectors, Atlas and CMS (Compact Krebs: LHC funds to be Muon Solenoid). part of US programme'. The National Science Foundation intends to spend an additional $\mathbf{\$ 8 0}$ million or so on the detectors, although it has yet to consider its contribution in detail, and officials say it could go higher.

In a bid to secure long-term congressional commitment to the LHC, Clinton's 1998 budget will spell out the planned US contribution in full. Most of the money will be spent between 1999 and 2002, once existing construction projects have been completed at Stanford Linear Accelerator Center in California and at Fermilab in Illinois.

But each year's contribution will be included in the main US high-energy physics budget, and will not appear as a separate line item in the budget. "We think of it as an integral part of our high-energy physics programme," says Krebs.

The US decision means that CERN will now be able to aim to complete the collider in 2005 - even though it has recently agreed to a reduction in the contributions of its member states (see Nature 385, 4; 1997). Without contributions from the United States and Japan, the LHC would have had to be built in two stages, with completion delayed until 2008 .

The United States has not yet signed its agreement with CERN to participate in the project, which has been under negotiation since the beginning of last year. But US officials say there are no major issues to be resolved and that the agreement which will enable the United States to participate without becoming a member of CERN - will be ready shortly.

If the collaboration goes ahead, as looks increasingly likely, it will be viewed as a considerable triumph for the US highenergy physics community in the aftermath of the cancellation in 1994 of the Superconducting Super Collider.

The last hurdle to be crossed is the Congress. Here, most key players are in favour of US participation in the collider project, and serious opposition has yet to surface. According to one supporter of the project, the only event that could derail it would be a serious outbreak of dissent within the physics community itself.

Colin Macilwain

\section{Science bodies seek 7.1 per cent increase for NSF}

Washington. Two leading US scientific societies are demanding an increase of 7.1 per cent in the budget of the National Science Foundation next year, arguing that this is the minimum needed to restore the spending power of its research grants to a little above their 1995 level.

The Federation of American Scientists for Experimental Biology (FASEB), whose member societies represent 43,000 biologists, backed the target at a conference last month, and it has since been endorsed by the American Chemical Society (ACS), representing 152,000 chemists and engineers.

But the American Physical Society (APS) has not yet endorsed the target, which some of its officials consider too high and too specific. Senior APS officials have written to President Bill Clinton asking for increases of 5 to 7 per cent in the basic research budgets of the Department of Energy, Department of Defense and NSF.

The Clinton administration is expected to propose lower increases for science agencies within its budget proposal for the 1998 financial year (which starts on 1 October 1997), due to be released in early February. In its initial proposal at the beginning of December, the administration's Office of Management and Budget offered flat funding to NSF and science accounts in the energy department, and a 2 per cent cut at the National Institutes of Health (NIH). After appeals from the agencies, it is now ready to propose increases of around 3 per cent for NSF and 4 per cent for NIH.

But FASEB argues that the NSF's \$3.3-billion budget for 1997 has 6.1 per cent less purchasing power than the 1995 funding because of inflation. The federation suggests that the 1998 budget should make up the gap and add an additional increment of 1 per cent. The NSF funds most non-biomedical university research in the United States.

"The NSF has taken a real whack, getting nothing for a couple of years," says John Suttie, FASEB president and professor of biochemistry and nutrition at the University of Wisconsin at Madison. He hopes the APS and others will rally behind the target soon: "It is helpful if everyone uses the same number," he says.

FASEB had earlier announced its target of a 6.5 per cent budget increase for the NIH. The targets are intended primarily to influence appropriations committees in the Congress, which will spend the summer considering the budgets for all federal agencies proposed next month by the Clinton administration.

One appropriations staff member said the societies were deluded in expecting that NSF could do as well as NIH, which benefits greatly from pro-health-care sentiment. But he backs the view that the NSF needs stronger and better organized support from the scientific community. NSF officials agree, and privately welcome the FASEB target as a rallying point for the agency's friends in the Congress.

Later this month, FASEB, APS and ACS will publicly unveil a plan to lobby jointly for the NSF and other basic science programmes (see Nature 384, 393; 1996). C. M. 